DOI $10.32726 / 2411-3417-2018-3-60-70$

УДК $323 ; 327 ; 355 ; 366,636$

\title{
ТАТЬЯНА ШАКЛЕИНА
}

\section{Внутриполитическая ситуация в Вашингтоне. Роль СМИ и российско-американские отношения}

Аннотачия. Отношения России и США после окончания холодной войны прошли разные этапы и к 2018 г., по оченкам многих российских и особенно американских политологов, вступили в новую холодную войну, суть которой объясняют по-разному. Мохно ли было избежать ее или она была запрограммирована историческими парадигмами? Избежать войны можно: многое, если не все, зависит от устремлений правящей элиты. Американский политический мейнстрим действует в рамках традиционной внешнеполитической парадигмы - воинственной, непримиримой, подпитываемой мощной информационно-идеологчческой кампанией, одна из челей которой - отвлечь американцев от кризисной внутриполитической ситуации, найдя внешнего врага в лице России.

Ключевые слова:Россия, США, СМИ, Д. Трамп, правящие партии, выборы 2016 г., холодная война, свобода слова, утечки информачии.

роисходящие в Вашингтоне события объясняются не только неудовлетворенностью части политической элиты результатами президентских выборов 2016 г. Кризисное состояние американской политической системы зреет давно, и прошедшие выборы лишь еще более обнажили существующие проблемы, прежде всего неудовлетворенность населения правящими партиями и их лидерами, избирательной системой, социально-экономической ситуацией. Рядовые американцы, особенно молодежь, начали высказывать опасения и сомнения относительно того, как реализуются демократические принципы и как действуют демократические институты в стране. Сложившуюся в Вашингтоне ситуацию можно было бы охарактеризовать как «политический спазм» ${ }^{\text {. }}$

1 Впервые термин «спазм» был использован А.Д. Богатуровым, который так охарактеризовал общемировую ситуацию после экономического кризиса 2008 г. Закончился ли этот спазм в мировой экономике, сказать трудно, так как Соединенные Штаты, контролирующие созданную на основе американского доллара в либерально-рыночном формате финансово-экономическую систему, держат мировую экономику в спазматическом состоянии, не желая радикально ее реформировать, стремясь сохранить свое доминирование и преимущество, добавив санкционную политику и торговую войну как средство сохранения существующего порядка. Отдельные страны пытаются вырваться из этого состояния, но результаты таких попыток, предпринимаемых Китаем, Россией, Турцией и рядом других стран, пока трудно предсказать, учитывая потенциал США и тех западных экономик, которые их поддерживают [См.: Богатуров].

Сведения об авторе: ШАКЛЕИНА Татьяна Алексеевна - заведующая Кафедрой прикладного анализа международных проблем МГИМо МИД России, ведущий научный соmрудник Института США и Канады РАН, доктор политических наук; shakleina-tania@ yandex.ru. 
Решение внутриполитических проблем - дело самих американцев, и можно было бы не так внимательно за этим следить.однако все, что происходит в Вашингтоне, оказывает прямое влияние на поведение США в мире и на политику в отношении России. Особая роль во всех разворачивающихся в США процессах принадлежит СМИ, которые нагнетают страсти не только в Америке, но и за ее пределами. (В этом от американских СМИ не отстают и британские.)

Хотя в глаза бросается своего рода разлад между действующей администрацией США и значительной частью американской политической элиты, основы внешнеполитического курса остаются неизменными: стремление к закреплению либерального мирового порядка с Америкой-центром сохраняется и лишь приобретает еще более жесткую форму [См.: Шаклеина 2018].

Американские политики не хотят мириться с тем, что в своем эволюционном развитии США испытывают трудности, через которые пришлось пройти многим державам, и так называемая исключительность Америки и ее несомненные преимущества не гарантируют ей «особого исключительного пути». Американцы не желают отказываться от своей исключительности, признавать себя членом мирового сообщества, где интересы и проблемы разных стран взаимосвязаны, а при решении как общих, так и национальных проблем необходимо учитывать интересы других.

Анализ ситуации в Вашингтоне не дает поводов для оптимизма, так как в том, что там происходит, нет пока намека на хотя бы минимальный отход от идеологии гегемонии во внешней политике, разного рода войн до победы, поиска врагов, перманентно угрожающих Америке [Bacevich 2010; 2013; Layne; Hendrickson]. На вопрос «Кто виноват?» и демократы, и республиканцы, и пресса, и политологи из ведущих «мозговых центров» дружно отвечают: недемократические внешние силы (прежде всего Россия). Большинство из них не хотят даже обсуждать внутренние факторы: серьезные социальные проблемы, вызвавшие столь глубокий раскол на выборах 2016 г.; изъяны политической системы; кризис обеих партий; состояние прессы, ее поведение и методы действия (соответствие 1-й поправке Конституции); заметный кризис в реализации международной стратегии и ряд других. Америка, полагают в Вашингтоне, по-прежнему незыблема и совершенна, появление такого деятеля, как Д. Трамп, случайность и происки внешних сил, непримиримость и жесткость в отношении несогласных внутри и за рубежом должны сохраняться.

События 2016-2018 гг. сравнивают с громкими разоблачениями и межпартийными столкновениями 1970-х годов. Это было время, когда в отношениях СССР и США происходила «разрядка». начался хельсинкский процесс, завершившийся в 1975 г. подписанием Хельсинкского акта, который ознаменовал важный прорыв в двусторонних отношениях и в Холодной войне. Разразившиеся в то время в США политические скандалы были сконцентрированы на внутренних проблемах и обошли стороной отношения с СССР. Конфликтующие стороны - правительство и СМИ, Демократическая и Республиканская партии - видели угрозу прежде всего в несовершенстве американских политических институтов и в нарушениях конституции. 
С тех пор на протяжении почти сорока лет исполнительная власть методично старалась защитить себя от разного рода «вторжений» со стороны прессы, а пресса все больше встраивалась в правительство, сживалась, сливалась с ним, становясь «придатком» правящей партии, а не институтом, стоящим над правительством. Это прежде всего касается сферы национальной безопасности. Но и в вопросах внутренней политики пресса оказывалась под влиянием партий и различных групп интересов (или открыто примыкала к ним, в зависимости от того, каких политических убеждений придерживались владельцы новостных корпораций и ведущих СМИ).

Еще в 1973 г. Д. Уайз, один из самых последовательных журналистов-аналитиков, занимавшихся проблемами взаимоотношений правительства и прессы, писал: «Американскую прессу часто называют «четвертой ветвью» власти, и этот термин отражает как ее необычайную важность, так и ее главную слабость. Ведь пресса не является ветвью власти, и степень забывчивости журналистов, или отождествление себя с правительством не позволяют им выполнять возложенную на них функцию служения обществу» [Wise, p. 25]. Сегодня пресса по-прежнему пытается олицетворять себя с «четвертой ветвью» власти.

Весьма актуально, на наш взгляд, еще одно точное замечание Д. Уайза, высказанное 45 лет назад. «Обман со стороны американского правительства, - писал он, - носит симптоматичный характер, а рост могущества Америки и превращение ее в мировую державу после Второй мировой войны усилили соблазн и возможности для правительства обманывать народ». Создание системы жесткого контроля над информацией, обращал внимание журналист, привело к тому, что сложилась своего рода «система институционального обмана». Д. Уайз все-таки надеялся, что правительство осознает преимущества более правдивого информирования американцев и это положит конец политике обмана [Wise, p. 500-501, 505-506].

Эти слова стоит взять на заметку. Ведь политика обмана продолжается, а пресса поддерживает такую политику, участвует в ней, и лишь немногие из журналистов озабочены проблемой более или менее адекватного информирования общества, чтобы «обмануть врага», по-прежнему обманывают американцев, многие из которых действительно мало что знают о происходящем в мире и не всегда могут разобраться в том, что происходит в их собственной стране'. А чтобы отвлечь внимание от внутреннего социально-политического кризиса, мейнстримные политики и журналисты объединяют усилия для создания «официальных» врагов и разработки «адекватных мер» по их нейтрализации.

Стоит ли удивляться аналогиям между тем, о чем писал Уайз, и тем, что происходит в наше время, или развитие американского государства в таком направлении было

1 Д. Уайз писал: «Очень часто политики, находящиеся у власти, оправдывают рост секретности и обман общественности тем, что иногда надо вводить в заблуждение американцев, чтобы обмануть врага. Такое объяснение неприемлемо ни с моральной, ни с философской точек зрения, и чаще всего это просто неправда. Чаще всего “враг” хорошо осведомлен о том, что происходит на самом деле, а вот американцы не знают ничего» [См.: Wise, p 501]. 
предсказуемо? Все без исключения администрации проводили линию на ужесточение контроля над доступом к правительственной информации, и это привело к почти полной зависимости прессы от правительства в получении сведений, особенно если речь шла о внешней политике. Время от времени «утечки» все-таки осуществлялись, как это происходит и сейчас в ходе политической борьбы в Вашингтоне [См.: Frank, Weisband; O'Brien; Reston; Schorr]. Но при такой технологии добывания информации журналистами вряд ли можно говорить о свободной американской прессе. Технология «утечек» и не всегда законные методы получения информации часто не позволяют проверить обнародованные журналистами факты, что только усложняет ситуацию. Но, может быть, как раз это и нужно политикам?

В 1990-е годы американский истеблишмент не видел серьезных препятствий для реализации поставленных задач по преобразованию мира, поэтому не было острой необходимости мобилизовывать СМИ и «мозговые центры» для поиска и «оформления» нового врага. Главными скандалами были внутриполитические, такие как коснувшееся демократов дело Моники Левински и другие скандальные сюжеты, традиционно сопровождавшие выборы, когда под огнем журналистов оказывались обе партии и их кандидаты.

В 2000-2010-е годы ситуация изменилась. Реализация планов США по строительству мирового порядка столкнулась с препятствиями. На авансцену вышли Россия и Китай, реальные оппоненты американской политики [Emerging Powers... Challenge and Change... Шаклеина 2017, p. 66-177]. Пресса быстро воодушевилась новой возможностью расширить свое участие в политике, освещая операции США в разных уголках мира. Когда же были четко определены новые враги Америки, действия прессы стали напоминать пропагандистские кампании времен Холодной войны, только уже с новыми техническими возможностями и в более широком масштабе. Как отмечал американский политолог Д. Хендриксон, Америка неохотно признает наличие национальных интересов у других держав и оценивает международную ситуацию, исходя из собственных представлений, собственной политической культуры, а не на основе объективной оценки происходящего. Коллективное самомнение американцев, писал политолог, их способность видеть во всем опасность и врагов с незапамятных времен делают политику Америки нацеленной прежде всего на борьбу «со злом». В этих условиях значительная часть прессы наделяется правом обвинять и выносить приговор той или иной стране. Получается, что «Америка нуждается во врагах, без них она потеряет свою идентичность» [Hendrickson, p. 58-59; Баталов, Журавлева, Хозинская; Баталов 2010; Баталов 2015].

Пресса - это часть Америки, ее политической системы, она действует в той же парадигме, что и правящая администрация. Поэтому, во-первых, она информирует американцев и остальной мир о том и в той степени, что и как допускается политическим мейнстримом (исключения существуют, но они немногочисленны), а во-вторых - занимается пропагандой официальной линии или интересов тех политических и экономических групп, с которыми ее связывают договоренности, нередко линия определяется владельцем той или иной новостной кампании или издания. 
«Утечки» информации были и остаются в массе своей контролируемыми. Количество не контролируемых президентом «утечек» увеличивается в периоды кризисных внутриполитических ситуаций. Именно такую переживает сегодня Вашингтон. Пресса в этой политической игре выступает не как независимый наблюдатель, а как ангажированный участник от разных политических партий и группировок. Есть заказ на создание образа внешнего врага, на которого можно свалить всю политическую неразбериху, назвав его к тому же угрозой американской демократии - заказ принят. И большинство СМИ (особенно либеральных) на этот заказ работает, надо сказать, с упоением. [Dionne, Ornstein, Mann, p. 97-99].

Иначе не понять, почему так быстро журналисты ухватились за российскую тему: Америке нужен реальный враг, и он есть, привычный и знакомый, - правда, с новым лицом. Не понять иначе, почему американские журналисты не озаботились по-настоящему правдивым информированием американцев во время таких событий, как военная операция в Ираке, а затем в Сирии. Во время первой на ведущих телеканалах шли лишь победные репортажи о действиях американских военных, всему миру показали казнь Саддама Хусейна, но ничего не было сказано о жертвах среди мирного населения, которые исчислялись сотнями тысяч. Появились лишь немногие публикации на эту тему, но вопрос быстро закрыли. Во время бомбардировок Сирии в апреле 2018 г. звучали победные заявления президента на фоне довольно сомнительных картинок о последствиях бомбардировок. Зато подробно показывали постановочные репортажи о последствиях использования химического оружия армией Б. Асада, а также постановочные репортажи из почти безлюдных лагерей беженцев. При этом - ничего из документальной хроники о реальном положении вещей в Сирии и о реальных действиях российских военных.

Что еще характерно для прессы США в XXI в., так это неверное выделение фокуса проблем американского общества и мира в целом. В 1960-1970-е годы было четко определено и заявлено, что угроза свободе слова и печати кроется внутри американской политической системы, прежде всего - в администрации, пытавшейся проводить тайные операции за рубежом и утаивать важную информацию об этом [См., например:Fulbright]. Нарастал разрыв между обществом, прессой и правительством. недовольство американцев смыкалось со стремлением разоблачительной прессы узнать правду о Вьетнаме, о кулуарных играх во время выборов, о незаконных поставках оружия и незаконном расходовании средств.

А что же происходит сейчас? Чего добивается пресса? Вместо того чтобы разобраться с кризисом во внутриполитическом истеблишменте, в деятельности обеих партий, в поведении кандидатов (а не только Д. Трампа), в изъянах проведения избирательных кампаний, пресса активно ищет внешнего врага, называя Россию угрозой американской демократии, хотя политическая система США подрывается изнутри. Журналисты и либеральных, и консервативных СМИ стараются перещеголять друг друга в добывании скандальной информации, но от этого ситуация не меняется. Проблема кризисного «спазма» политической системы остается нерешенной. 
Потерпев поражение в 2016 г. вместе с кандидатом демократов, либеральная пресса «обиделась» на консервативную прессу, которая нарушила монополию либералов и опередила их технически, обрушилась на консервативные масс-медиа и обвинила их во всех бедах Америки [Dionne, Ornstein, Mann]. Но затем и те и другие СМИ сконцентрировались на внешнем враге, оперируя непроверенными и недоказанными фактами. В результате многие американцы перестали смотреть ведущие телеканалы и читать печатные издания, так как невозможно разобраться в истинных событиях в Вашингтоне и в мире, включая российско-американские отношения. И все-таки значительная часть американцев смотрит и читает, и на них СМИ оказывает такой информационный эффект, который сродни полному отсутствию информированности. Это очень опасно. Ситуация напоминает американскую комедию 1966 г. «Русские идут!» (Russians are coming!), в которой авторы с юмором показали, до какого абсурда дошли страхи простых американцев в результате нагнетания и подачи искаженной информации об СССР'.

После выборов 2016 г. вопрос о прессе, ее роли, взаимодействии с партиями вновь стал предметом обсуждений. Большую активность проявляли сами журналисты и комментаторы, пытаясь имитировать действия журналистов 1970-х годов. Но при этом они заботились не о восстановлении престижа и объективности СМИ, прежде всего разоблачительной журналистики. Как и в прошлом, чтобы отвлечь общество от реальных проблем в деятельности американского руководства и СМИ, начались раскручивание внешней угрозы, поиски и демонизация внешнего врага, следствием чего стали и рост военного бюджета, и «спектакль» с бомбардировками в Сирии.

Справедливости ради надо сказать, что началось это не при Д. Трампе: закрепил «врага» в официальных документах Б. Обама [National Security...Mann; Layne; Lieven]. Но он был либералом, «своим» для основных новостных корпораций, ориентированных на демократов. поэтому именно при президенте-республиканце - особенно таком противоречивом в своих заявлениях и действиях, как Д. Трамп - наступил момент, когда оказалось возможным одновременно отвлечь внимание от того, что «наделали» до Трампа, и обрушить один мощный удар и на президента, и на его команду, и на прессу и журналистов, не работающих на Демократическую партию, и на Россию, выставив ее угрозой американской демократии [Russia and the United States... p. 5-11, 12-57; Shakleina 2016].

1 На проходившей в 1979 г. в США выставке «Советская женщина» американцы поражались всему: одежде, прическам, поведению. У них было странное представление о советских женщинах как об угнетенных существах, ходящих в телогрейках и валенках, ничего не знающих о моде. На выставке был представлен в том числе Московский дом моделей, проходили показы, американцы с удовольствием выстраивались в очередь, чтобы пригласить участников выставки к себе домой, хотели узнать больше обо всем: школах, книгах, быте и т.д. Советских людей это удивляло, они были хорошо осведомлены о международных отношениях, о политике США, отношениях между двумя странами, хотя конечно, не знали жизни обычных американцев в деталях. В 2010-х годах американцы снова стали задавать странные вопросы о том, не страшно ли жить в России, работает ли там отопление, нет ли голода и т.д. Родители стали бояться отпускать детей в Россию учиться, на чемпионат мира по футболу. Такое положение сложилось из-за тех материалов, которые публиковались в СМИ и показывались по телевидению. 
Интересно, как оценивают сложившуюся политическую и социально-экономическую ситуацию либеральные авторы, как они трактуют поражение либеральной прессы. Они сетуют на то, что после администрации Р. Никсона антагонизм между либеральной и консервативной прессой углублялся, что развитие информационных технологий и интернета лишило безраздельно господствовавшие печатные органы и телеканалы либерального направления их доминирующих позиций в формировании общественного мнения и политической жизни страны. Главный упрек адресуется республиканцам, прежде всего Р. Рейгану, и состоит в том, что это они объявили войну мейнстримной прессе. Но это была не столько война, сколько целенаправленная деятельность, характерная для всех администраций, включая демократические, по формированию жесткой системы контроля над правительственной информацией и упорядочению системы «утечек». Антагонизм между властью и прессой в той или иной степени существовал всегда. Вопрос в том, кто контролирует основные СМИ, какие группы интересов за ними стоят, насколько совпадают интересы данных групп, включая владельцев новостных корпораций и печатных органов, и правящей администрации'.

Хотя согласно Конституции США пресса должна отвечать интересам народа и информировать его, партийная ориентация в той или иной степени в СМИ присутствует. есть она и у «мозговых центров», хотя они это отрицают. Она довольно легко просматривается в содержании материалов СМИ, в комментариях, тональности подачи новостей или аналитической информации, в выборе вопросов, даже в манере проведения новостных передач или ток-шоу, в подборе приглашенных экспертов и политиков. И дело здесь не в том, какие это СМИ, консервативные или либеральные, а в том, что они используют сходные технологии. Конкуренция между разными СМИ стала неотъемлемой частью политической системы и с каждым годом только усиливается.

То, что либеральные СМИ, господствовавшие в XX столетии, оказались обойденными, сильно разозлило либералов. Они обвинили консервативные СМИ в том, что те более активно использовали интернет и другие передовые политические и информационные технологии. Действительно, произошли колоссальные изменения, как сугу-

1 Иногда в качестве примеров «доверительных» отношений президента и прессы приводят администрации Ф.Д. Рузвельта и Дж. Ф. Кеннеди. Представляется, что большую роль в этих случаях играла харизматичность обоих лидеров, сохранявшаяся определенная степень доверия правительству и осторожность в обращении с внешнеполитической информацией, чему был положен конец расцветом разоблачительной журналистики с последующим ее превращением в погоню за скандальной информацией, которую можно было выгодно «продать» заинтересованным сторонам в нужный момент. Последний пример тому - поведение бывшей сотрудницы аппарата Белого Дома Омаросы Маниголт-Ньюман, обнародовавшей разоблачительную информацию на Д. Трампа. Она заявила, что это была не вся информация, записанная ею на магнитофон за все время работы, и остальную часть информации она обнародует тогда, когда наступит «нужный», на ее взгляд, момент. Не отрицая важность разоблачительной журналистики, следует отметить, что практика тайного подслушивания и записей с последующим обнародованием информации (в том числе, сугубо личного характера), которой пользуются не только журналисты, но и служащие разных ведомств и компаний, наводит на мысль о ситуации, которую описал Дж. Оруэлл в романе «1984». 
бо технические, так и политические, которые сильно изменили новостной ландшафт. А поскольку американское общество живет по законам рыночной экономики (как утверждают американские политики), то и конкуренция довольно жесткая. Происходящие в информационной сфере необратимые процессы сказались на печатных органах, крупнейших газетах и журналах, пострадали и ведущие телеканалы. Как отмечали аналитики, если в 1980 г., когда начала работу компания Си-Эн-Эн, 75\% телевизоров были настроены на один из трех ведущих телеканалов: Эй-Би-Си, Эн-Би-Си, Си-Би-Эс, то в 2003 г. таких стало только 40\%. В 1980 г. смотрели вечерние новости по одному из этих трех телеканалов 52,1 млн американцев, а в 2017 г. таковых было только 25 млн. «Три гиганта» (Big Three), контролировавшие информационное пространство, утратили этот контроль, так как стали появляться другие новостные каналы, имевшие большее финансирование и более активно пользовавшиеся новейшими техническими возможностями.

Особенно печальная судьба постигла газеты, многие из которых исчезали, лишившись дополнительного финансирования, поступавшего от партий или штатов и не выдерживая конкуренции с телевидением. Их число уменьшалось также в связи с крахом связанных с местными газетами сетевых универмагов, на смену которым пришли торговые центры (моллы), взаимодействовавшие с покупателями напрямую по телефону и электронной почте, использовавшие для рекламы интернет. Число журналистов-газетчиков сократилось с 457800 в 1990 г. до 183200 в 2016 г. За это же время число сотрудников, работающих в интернет-изданиях и на радио, выросло с 29700 до 197800 [Dionne, Ornstein, Mann, p. 53-57].

«Мозговые центры» тоже существенно изменили формы деятельности. Сократилось число крупных аналитических работ, большая часть аналитической информации стала подаваться в виде коротких комментариев и высказываний в блогах и твиттерах [McGann]. Требование к использованию таких форм взаимодействия с аудиторией стало обязательным для аналитиков. Это гораздо дешевле и проще подготовки всесторонних и детальных работ по той или иной проблеме. «Журнализм мнений» или «аналитика мнений» существовали и раньше, однако они не имели такой значимости. Известный в 1970-е годы журналист Д. Мойнихем писал, что «каждый может придерживаться своего собственного мнения, но не своих собственных фактов». Имелось в виду, что журнализм, основанный на мнениях, только тогда может считаться журналистикой, если основывается на достоверных (проверенных) фактах. Проблема в том, что не всегда журналисты оперируют достоверными фактами и подают их в полном объеме, а проверить это не так просто. Как заметила одна из журналистов «Нью-Йорк таймс» М. Какутани, «старым понятиям “правда” и “знание" угрожает закрепление новых понятий - “мнение” и “восприятие”, и впереди нас ожидает «мир, в котором “правда” будет заменена “мнением” [Dionne, Ornstein, Mann, p. 58-59].

Фактор личного мнения аналитика или комментатора, как его собственного, так и сопряженного с каким-либо коллективным мнением (партии, группы, редакции, руководства фонда и т.п.), приобретает все большую значимость. Это общая тенденция, 
характерная не только для американских СМИ. Произойдет ли поворот к росту и большей востребованности серьезной аналитики и серьезных комментариев с опорой на реальные факты, а не на нераскрываемые «источники информации», трудно сказать. Обвиняя консервативную прессу в наступлении на прессу либеральную с использованием всех новых технических средств, либеральные критики обеспокоены прежде всего утратой собственных доминирующих позиций в новостной сфере. Они хотят вернуть себе преобладание. Но разве в этом заключается главная дилемма политической жизни Америки? Она, как представляется, в другом: как сделать СМИ более объективными, как вывести их из партийной зависимости (если это возможно), как остановить рост пропаганды в деятельности масс-медиа, превращающей их в средство нагнетания мнимых страхов и игнорирования истинных угроз. Дискуссия о правде и лжи в СМИ, начатая в связи с выборами 2016 г., не всегда идет в адекватном русле. Концентрируя дискуссию вокруг личности президента Трампа, бросившего вызов прессе и не посетившего официальный ужин Ассоциации корреспондентов Белого Дома, журналисты и политологи в массе своей уходят от сути проблемы: почему так много неверной информации появляется на телевидении и в СМИ в целом? Почему пресса выступает в роли прокурора, обвиняя, в частности, Россию в недоказанных действиях, не дает полной и правдивой информации о том, что происходит в странах, где проводили свои операции США и НАТО? Об этом пишут авторы, которых волнует судьба Америки и судьба американской журналистики, имеющей богатую историю разоблачительной деятельности.

Сам факт появления на политическом небосклоне и победы Д. Трампа свидетельствует о том, что в американском обществе накопились и дали о себе знать процессы и проблемы, которые переживали и продолжают переживать многие страны. Это межэтнические и межрасовые отношения; миграция законная и незаконная; усложнение социально-экономической ситуации; сбои функционирования политической системы, включая кризис обеих правящих партий; сложности в электоральной системе и многое другое [Drezner; Anderson; Pillar]. Все это важные, требующие внимания проблемы. Имеет место дефицит лидеров на партийном уровне, существует необходимость менять избирательную систему, есть недовольство исполнительной властью и той политикой, которую она проводит. Никто извне эти проблемы для Америки не создавал. Поиск внешних причин их не решит, ситуация может только усложниться.

Многие страны немало позаимствовали у Америки, она долгое время рассматривалась как своего рода эталон для подражания. Сохранилось ли такое же отношение к ней сейчас? Сомнительно. Хотя по-прежнему многим Америка видится как страна возможностей, мало кому импонирует американская непримиримость, доведенная до степени открытой воинственности и нетерпимости. Когда слушаешь или читаешь отдельных американских авторов, поражает степень их НЕтолерантности. Даже в академической, научной среде вполне откровенно подавляются мнения, не совпадающие с общепринятыми. Молодому специалисту-международнику трудно отстаивать свои позиции, только недосягаемо авторитетным независимо мыслящим специалистам удается выдерживать критику и напор. 
Американцам есть чем заняться дома, поэтому им вряд ли стоит все время поучать остальных, искать повсюду врагов и шокировать остальной мир заоблачными военными расходами. «Остальные», если захотят, сами позаимствуют у Америки то, что их привлекает. Но то, что весь мир видел во время и после выборов 2016 г., малопривлекательно, не говоря уже о действиях США в экономической сфере и в сфере безопасности. Учиться этому не стоит. От таких проявлений «авторитарного либерализма» следует уклоняться и все-таки сдерживать их. Для этого у ведущих стран мирового сообщества есть силы и возможности. И может быть, нынешним американским политикам и экспертам-международникам нужно внимательней и серьезней прислушаться к тому, что писали о миссии Америки Дж. Кеннан, У. Фулбрайт, С. Хантингтон, а сейчас, несмотря ни на что, говорят Э. Басевич, Дж. Миршаймер, А. Ливен, К. Лэйн и другие умные и честные политологи, не только заботящиеся о своей стране, но также думающие о будущем других стран, которым нужны мир и стабильность и не нужны никакие войны.

\section{Литература}

Баталов Э.Я. Американская политическая мысль XX века. М. 2015.

Баталов Э.Я. Проблема демократии в американской политической мысли XX века. М. 2010.

Баталов Э.Я., Журавлева В.Ю., Хозинская К. В. «Рычащий медведь» на «диком Востоке». Образы современной России в работах американских авторов: 1992-2007 гг. М. 2009.

Богатуров А.Д. Политический спазм в глобальном масштабе // Международные процессы. Том 8. Номер 3(24). Сентябрь-декабрь 2010.

Шаклеина Т.А. Какая Америка нужна миру? // Международные процессы. Т. 16. № 1. 2018. C. 40-52.

Шаклеина Т.А. Россия и США в мировой политике. Изд. 2-ое, испр. и доп. М. 2017.

Anderson C. White Rage. The Unspoken Truth of Our Racial Divide. N.Y. 2017.

Bacevich A. Washington Rules. America's Path to Permanent War. N.Y. 2010.

Bacevich A. Breach of Trust. How Americans Failed Their Soldiers and Their Country. N.Y. 2013.

Emerging Powers in a Comparative Perspective. The Political and Economic Rise of the BRIC Countries / ed. by V. Nadkarni and N. Noonan. N.Y. 2013.

Challenge and Change. Global Threats and the State in Twenty-First Century International Politics / ed. by N. Noonan and V. Nadkarni. N.Y. 2016.

Dionne E.J., Jr., Ornstein N.J., \& Mann Th.E. One Nation after Trump. A Guide for the Perplexed, the Disillusioned, the Desperate, and the Not-Yet Deported. N.Y. 2017.

Drezner D.W. The Ideas Industry. N.Y. 2017.

Frank Th., Weisband E. (eds.) Secrecy and Foreign Policy. N.Y.1974.

Fulbright J. W. The Arrogance of Power. N.Y. 1966.

Hendrickson D. Republic in Peril. American Empire and the Liberal Tradition. N.Y. 2018.

Huntington S. Dead Souls. The Denationalization of the American Elite // The National Interest. 2004. No. 75. Pp. 5-18.

Layne Ch. The Peace of Illusions. American Grand Strategy from 1940 to the Present. Ithaca. 2006. Lieven A. America Wright or Wrong. An Anatomy of American Nationalism. $2^{\text {nd }}$ ed. N.Y. 2012.

Mann J. Obamians. The Struggle Inside the White House to Redefine American Power. N.Y. 2012. 
McGann J. The Fifth Estate. Think Tanks, Public Policy, and Governance. Wash., D.C. 2016. Mearsheimer J.J., Walt S.M. The Case of Offshore Balancing. A superior U.S. Strategy // Foreign Affairs. Vol. 95. No. 4 (July/August 2016). Pp. 70-84.

National Security Strategy of the United States of America. 2015. — URL: whitehouse.gov/sites/ default/files/docs/2015_national_security_strategy_2.pdf (date of access: 13.09.2018).

O'Brien M. The Public's Right to Know. Supreme Court and the First Amendment. N.Y. 1981.

Pillar P.L. Why America Misunderstands the World. National Experience and Roots of Misperception. N.Y. 2016.

Reston J. The Artillery of the Press. Its Influence on American Foreign Policy. N.Y. 1967.

Russia and the United States in the Evolving World Order / ed. by A. Torkunov, N. Noonan, T. Shakleina. M. 2018.

Shakleina T. Common Traits and Differences in Russian-American Relations / T.A.Shakleina // International Trends (Almanac 2016). Volume 2. №3 (4). Pp. 23-33.

Shakleina T. Cold War as Part of American Global Strategy // International Trends. 2016. Vol. 14. № 1. P. 39-46.

Schorr D. Clearing the Air. N.Y. 1978.

Wise D. The Politics of Lying. Government Deception. Secrecy, and Power. N.Y. 1973. 